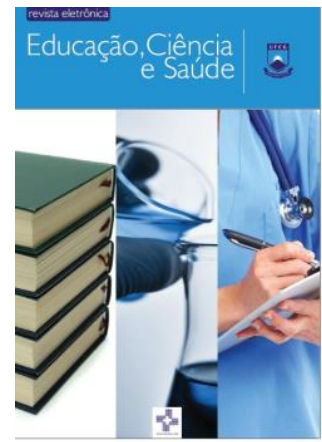

EDUCAÇÃO CIÊNCIA E SAÚDE

http://dx.doi.org/10.20438/ecs.v5i2.193

\title{
RELATO DE EXPERIÊNCIA DA MONITORIA ACADÊMICA NA DISCIPLINA DE QUÍMICA ANALÍTICA II: COMPARTILHANDO CONHECIMENTOS
}

\author{
Lorena Vanessa Medeiros Dantas ${ }^{1}$, Thays Milena Silva Lopes², Denise \\ Domingos da Silva ${ }^{3}$ \\ ${ }^{1}$ Curso de Licenciatura em Química, Unidade Acadêmica de Educação, Universidade Federal \\ de Campina Grande, Cuité-PB, Brasil. \\ ${ }^{2}$ Curso de Bacharelado em Farmácia, Unidade Acadêmica de Saúde, Universidade Federal de \\ Campina Grande, Cuité-PB, Brasil. \\ ${ }^{3}$ Professora Unidade Acadêmica de Biologia e Química, Centro de Educação e Saúde, \\ Universidade Federal de Campina Grande, Cuité-PB, Brasil. \\ Email para correspondência: dedomingos@gmail.com
}

\begin{abstract}
Resumo
Este artigo constitui o relato de experiência das atividades de monitoria acadêmica da disciplina de Química Analítica II, realizadas por alunas dos cursos de Farmácia e Química da Universidade Federal de Campina Grande-PB. Os objetivos da experiência em questão visaram despertar nas monitoras o interesse pela docência e promover a consolidação dos conhecimentos adquiridos anteriormente com participação do processo de ensino-aprendizagem na disciplina de Química Analítica II junto com os acadêmicos e professora orientadora. Foram realizadas atividades de auxílio à professora docente na organização de listas de exercícios, auxílio nos seminários realizados pelos alunos e aula prática no laboratório. Concluiu-se que o Programa de Monitoria revelou-se um instrumento motivador do processo ensino-aprendizagem uma vez que desperta nos monitores o interesse pela pesquisa e docência, bem como leva ao aperfeiçoamento para formação profissional. O programa torna a experiência da graduação do monitor mais rica e promissora, além contribuir para o aprendizado dos acadêmicos.
\end{abstract}

Palavras-chave: Relato de Experiência, Monitoria, Química Analítica II.

\begin{abstract}
This article is the experience report of the activities of academic monitoring of the discipline of Analytical Chemistry II, carried out by students of the courses of Pharmacy and Chemistry of the Federal University of Campina Grande-PB. The objectives of the experiment in question aimed to awaken in the monitor the interest to teaching and to promote the consolidation of the knowledge acquired previously with participation of the teaching-learning process in the discipline of Analytical Chemistry II together with the academics and the teacher. Activities were carried out to help the teaching teacher in the organization of lists of exercises, help in the seminars held by the students and practical classes in the laboratory. It
\end{abstract}


was concluded that the Monitoring Program proved to be a motivating instrument of the teaching-learning process since it arouses in the monitors the interest to research and teaching, as well as leads to the improvement for professional training. The program makes the monitor's graduation experience richer and more enriching, as well as contributing to the learning of academics.

Keywords: Experience Report, Monitoring, Analytical Chemistry II

\section{Introdução}

A educação superior é dividida no ensino em Licenciatura e Bacharelado que diferem em conformidade com o perfil de formação e intervenção profissional. Os cursos de licenciatura preparam o profissional para atuar como docente na educação básica e superior, e os cursos de bacharelado para a indústria, pesquisa e também para o ensino superior. No ensino para o nível superior, foram implantadas novas diretrizes curriculares, dentre as quais o Programa de Monitoria, que surgiu como uma atividade complementar pedagógica dos cursos para formação do estudante (SANTOS, ANACLETO, 2007).

As monitorias acadêmicas foram consolidadas nas universidades brasileiras a partir a Lei $n^{\circ} \mathbf{5 . 5 4 0 / 6 8}$, onde preconiza que as universidades ofereçam seleções para monitores a partir de seleções específicas para demonstrarem o desempenho em determinadas disciplinas (BRASIL, 1968, apud DANTAS, 2014).

O programa de monitoria proporciona a oportunidade tanto para o aluno monitor que tem como objetivo realizar pesquisas, dinâmicas, atividades auxiliando o docente, aprofundar conhecimento e experiência que promovem o desenvolvimento da vida acadêmica, a percepção da importância da ética, da constante atualização e do empreendimento na própria formação, quer seja como profissional do mercado de trabalho ou como pesquisador da área de ensino e ciência (MATOSO, 2014). Por outro lado, o professor necessita planejar estratégias e elaborar o plano de trabalho para as atividades realizadas em sala de aula, supervisionar as atividades realizadas pelo aluno monitor, além de viabilizar oportunidade ao aluno para que ele acompanhe as atividades didático-científicas (SANTOS, NASCIMENTO, 2014).

O aluno monitor experimenta, em seu trabalho docente, de forma amadora, os primeiros júbilos e contratempos da profissão de professor universitário. $O$ fato de estar em contato direto com alunos, na condição 
também de acadêmico, propicia situações extraordinárias e únicas, que vão desde a alegria de contribuir, pedagogicamente, com o aprendizado de alguns, até a momentânea desilusão em situações em que a conduta de alguns alunos se mostra inconveniente e desestimuladora. O exercício extraclasse de monitoria, também, permiti que os monitores tenham a construção de vínculos diferenciados dentro da universidade, ampliando o contato com a equipe docente e com as questões administrativas. A monitoria também contribui na construção de um currículo eficiente para um candidato potencial a mestrado, a concurso público ou ao mercado de trabalho (NATÁRIO; SANTOS, 2010; OLIVEIRA, ROCHA, PEREIRA, 2014).

Desta forma, podemos exaltar a importância da implementação do programa de monitoria nas disciplinas do ensino superior, pois excede 0 caráter de obtenção de um título, seja no aspecto pessoal de ganho intelectual do monitor, seja na contribuição dada aos alunos monitorados e, principalmente, na relação interpessoal de troca de conhecimentos entre os professores da disciplina e o aluno monitor.

A monitoria é uma atividade de grande relevância para a formação discente, no qual se objetivou despertar nas monitoras o interesse pela docência e promover a consolidação dos conhecimentos adquiridos anteriormente com participação no processo de ensino-aprendizagem na disciplina de Química Analítica II junto com os acadêmicos e professora orientadora.

\section{Metodologia}

O atual trabalho é de caráter descritivo, do tipo relato de experiência, realizado a partir da vivência discente durante a monitoria da disciplina de Química Analítica II, ofertada pela coordenação do curso de licenciatura em química, da Universidade Federal de Campina Grande (UFCG), Unidade Acadêmica de Biologia e Química, Campus Cuité, para o ano letivo de 2018, nos semestres de 2018.1 e 2018.2 .

A seleção para monitor desta matéria acontece semestralmente baseada em uma prova teórica de conhecimentos da matéria aos alunos que cursaram 
com êxito, no entanto, se os monitores selecionados no primeiro semestre do ano conseguirem obter êxito durante a monitoria e desejarem continuar como monitores acontece o processo de renovação de contrato.

A monitoria foi realizada sob orientação da Professora de Química Analítica II da UFCG nos cursos de graduação de Química Licenciatura e Farmácia Bacharelado, a disciplina possui a mesma ementa para os distintos cursos, entretanto, a explanação e abordagens possuem enfoques diferenciados, aonde se consegue abranger os dois cursos quando as turmas são mescladas.

Diante de todas as atividades desenvolvidas, foi feita a tabela 1 para orientar os monitores com seus deveres e não deveres, que estão inseridas no edital de seleção.

Tabela 1: Visualização dos pontos entre competências e proibições do monitor

\begin{tabular}{|c|c|}
\hline Competências do Monit & Proibições do Monitor \\
\hline $\begin{array}{l}\text { - Cumprir pontualmente os horários } \\
\text { de monitoria estabelecidos no início } \\
\text { do semestre; } \\
\text { - Avisar com antecedência quando } \\
\text { não for possível haver a monitoria } \\
\text { para que os alunos não percam } \\
\text { tempo; } \\
\text { - Zelar pela conservação da } \\
\text { Universidade, assim como relatar } \\
\text { todos os acontecimentos que vierem } \\
\text { a ser de seu conhecimento e que } \\
\text { culminaram nos problemas } \\
\text { apresentados; } \\
\text { - Zelar pela conservação dos } \\
\text { equipamentos, livros e outros } \\
\text { materiais colocados a sua }\end{array}$ & $\begin{array}{l}\text { - Qualquer tipo de atrito entre os } \\
\text { alunos a fim de evitar situações } \\
\text { constrangedoras. Caso ocorra } \\
\text { qualquer situação incontrolável, o } \\
\text { monitor deve chamar imediatamente } \\
\text { um professor ou funcionário da } \\
\text { Universidade; } \\
\text { - Ministrar aulas no lugar do } \\
\text { professor; } \\
\text { - Acessar dados confidenciais de } \\
\text { professores, alunos, funcionário ou } \\
\text { secretaria; } \\
\text { - Resolver exercícios ou fazer } \\
\text { trabalhos (parcialmente } \\
\text { completamente), como também impor } \\
\text { seu modo de programar, estudar ou }\end{array}$ \\
\hline
\end{tabular}




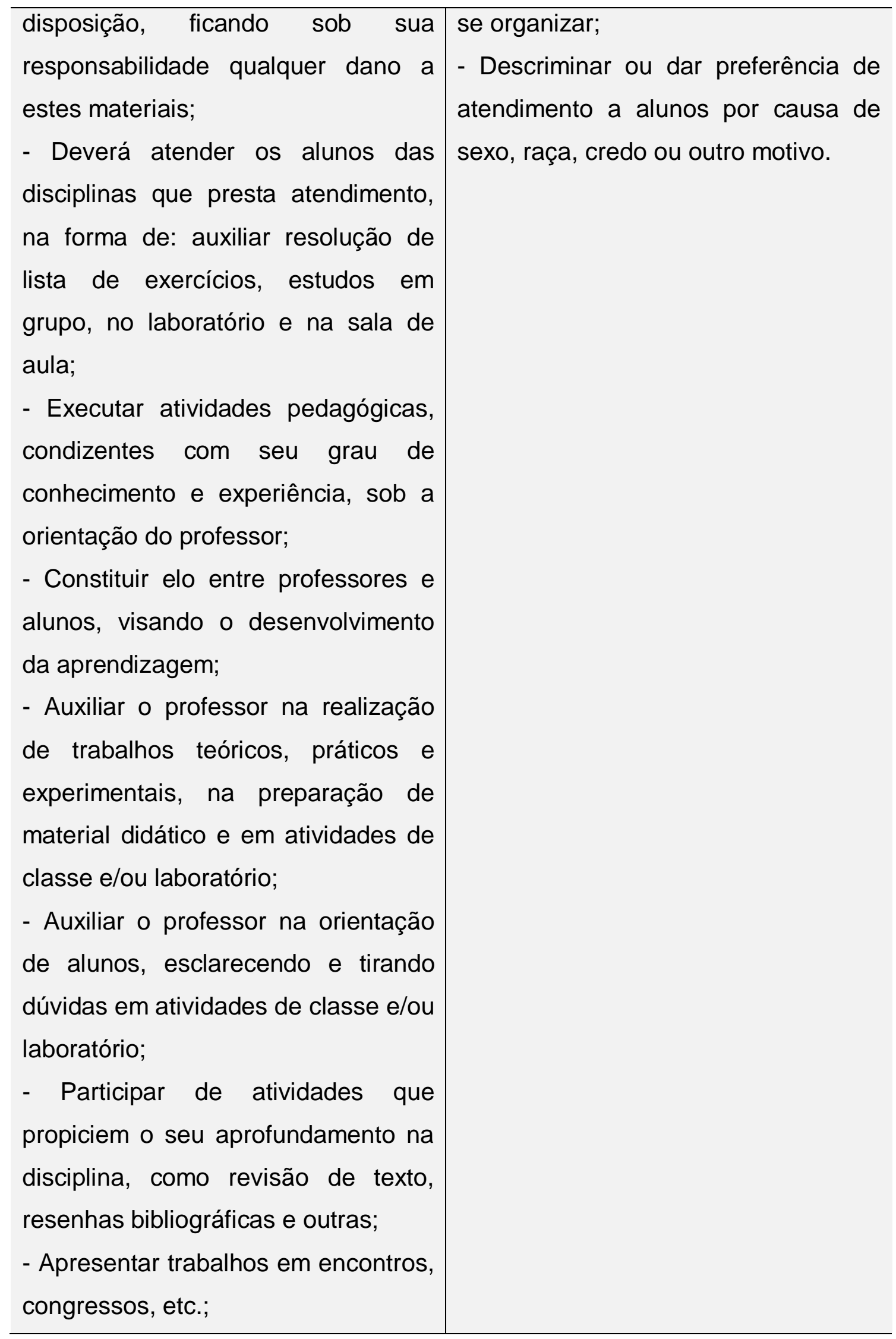


Por meio desta tabela 1 o monitor aprovado na disciplina tem a facilidade de saber o que cabe as suas atribuições ou não, podendo assim, conseguir organizar seus afazeres da melhor forma possível, evitando qualquer constrangimento que possa surgir durante o período de monitoria.

\section{Atividades desenvolvidas}

Foi disponibilizado aos alunos o contato das redes sociais das monitoras (whatsapp, facebook e e-mail), e criou-se um grupo da turma no Facebook (privacidade secreto) onde a professora orientadora também estava inserida, e outro grupo no whatsaap que foi utilizado com o intuito de facilitar a comunicação entre monitores e alunos.

Durante os encontros para monitoria tudo aconteceu da melhor forma possível, os alunos sempre procuravam, no entanto quando comparamos os semestres de 2018.1 e 2018.2, percebemos que no primeiro semestre houve uma maior busca pelas monitorias, e conseguimos identificar que os alunos do semestre 2018.1 tinham mais dificuldade com os assuntos da disciplina.

Os encontros com os educandos nas aulas práticas foram bastante proveitosos, onde os alunos conseguiram assimilar o conceito que, muitas vezes, quando estudado apenas teoricamente é um pouco mais complexo de se entender. Conseguimos ajudá-los de maneira significativa, onde tiveram a oportunidade de entrar em um laboratório e vivenciaram as técnicas exigidas para ser um bom analista, fazendo-se relação com a teoria dada em sala e aula.

Assim, com todos esses encontros e meios de comunicação os alunos puderam ter acesso mais rápido as monitoras, para que as dúvidas não ficassem sem soluções, estreitando, dessa forma, a troca de informações, facilitando a elucidação de dúvidas e promovendo uma melhor comunicação entre monitor-aluno-professor.

\section{$4 \quad$ Resultados e discussões}

A monitoria acadêmica é uma modalidade de ensino-aprendizagem que foi regulamentada através da Lei Federal ํㅜ 5.540, de 28 de novembro de 1968 (BRASIL, 1968), cujos objetivos estão voltados para a formação integrada dos 
alunos nas atividades institucionais que tangem as áreas acadêmicas de ensino, pesquisa e extensão dos cursos de graduação (LINS et. al., 2009). É compreendida como ferramenta para a melhoria do ensino de graduação, através do estabelecimento de novas práticas e experiências pedagógicas, que destinam a fortalecer a articulação entre teoria e prática e à integração curricular em seus diferentes aspectos e saberes, tendo por propósito promover a cooperação mútua entre discente e docente e a vivência com o professor e com as suas atividades técnicas e didáticas.

A Lei de Diretrizes e Bases da Educação Nacional - LDB (Lei № 9.394/96) ressalta a importância dos Programas de Monitoria na formação dos estudantes de nível superior e, em seu artigo 84, prevê que:

Os discentes da educação superior poderão ser aproveitados em tarefas de ensino e pesquisa pelas respectivas instituições, exercendo funções de monitoria, de acordo com seu rendimento e seu plano de estudos (BRASIL, 1996).

O aluno-monitor, ou apenas monitor, é o estudante que, interessado em progredir, aproxima-se de uma disciplina ou área de conhecimento e, junto a ela, realiza pequenas tarefas ou trabalhos, que contribuem para o ensino, a pesquisa ou o serviço de extensão à comunidade dessa disciplina.

Ao darmos essa assistência estudantil, nós tivemos o comprometimento e a fidelidade de estar sempre disponíveis para os alunos na carga horária proposta segundo as normas do Programa de Monitoria, tornando possível a construção de auto responsabilidade. Conforme argumenta Villas Boas (2006, p. 186), "[...] quem realiza o trabalho é quem o conhece melhor. Estudantes familiarizados com a autoavaliação geralmente avaliam-se adequadamente e são mais capazes de encontrar deficiências em suas produções do que outras pessoas". Enquanto monitoras é possível nos autoavaliar e saber quando existe necessidade de melhorar a preparação para as monitorias posteriores.

Nossas atividades se distribuíam desde o auxílio da preparação de listas de exercícios, resolução de possíveis dúvidas que surgissem, sendo estas retiradas em uma sala destinada a monitoria e a participação em aulas práticas no laboratório, como também, de forma menos frequente, a disponibilidade das nossas redes sociais para melhor ser o atendimento. Sergio Amaral fala da 
naturalidade com que ocorre esse processo do uso da tecnologia e redes sociais, quando argumenta que:

"A tecnologia, propriamente dita, presente na internet não é questionada enquanto aparato técnico, pois ela adquiriu uma determinada transparência que Ihes permite lidar com pessoas, informações, jogos, serviços, aplicações e amigos." (AMARAL in SILVA, coord., 2003:46)

Cada atividade realizada contribuiu de forma direta como bagagem de conhecimento para conosco, além de termos cursado a disciplina anteriormente, podemos de certa forma nos aprofundar nela, pois tínhamos que estar constantemente estudando para estarmos preparadas para qualquer questionamento que o aluno nos fizesse. Masetto (2003) diz que, quando o monitor auxilia na preparação da aula, ele pode verificar se a linguagem utilizada pelo professor, e as estratégias de ensino propostas estão compreensíveis aos discentes quanto na discussão dos encaminhamentos do trabalho docente que serão desenvolvidos com os graduandos.

Dentre as atividades, a mais gratificante foi à participação nas aulas práticas, pois não estávamos apenas auxiliando com a teoria e sim com a prática, sempre os amparando para fazer as titulações da maneira correta de acordo com as instruções de nossa orientadora.

Podemos dizer que a competência da teoria e da prática é dedicada ao professor-orientador para o desempenho do trabalho, agindo para ocorrer à produção do conhecimento. Com a presença do monitor pode-se fazer um acompanhamento mais aproximado de como o acadêmico pensa em sua formação no momento anterior a prática. Algumas vezes o monitor age como um "porta voz" da turma, levando ao professor por estar mais próximo apelos ou pedidos que talvez não chegassem até o mesmo e que quando chegam é de forma tardia (AZEVEDO, 2007).

A monitoria também proporciona um ambiente mais confortável para os alunos, pois muitas vezes monitor/monitorado são colegas ou amigos, o diálogo sobre a disciplina acontece de maneira mais espontânea e descontraída, tornando aquele momento agradável para ambos.

Há cada novo encontro da turma com o professor ou monitor, ocorre um processo de ensino-aprendizagem que se reatualiza. Ao professor cabe 
promover um espaço em que o monitor consiga desempenhar suas atividades extraclasses de maneira facilitada e entrando em consenso com as demandas acadêmicas, além disso, essas atividades geram ensaios para formação e capacitação para a carreira docente. (AZEVEDO, 2007).

Em concordância com a teoria da ação comunicativa de Habermas (1990), os sujeitos (monitor/monitorados) podem coordenar ações para alcançar objetivos comuns, de modo que os acordos construídos a partir das diferenças provenientes da diversidade de concepções devem ser fixados conscientemente por meio do diálogo entre ambos. Entendemos que essa diversidade, de fato, contribui para a melhoria do processo de ensinoaprendizagem, pois ao refletirem e dialogarem acerca das situações de aprendizagem vivenciadas, todos os sujeitos aprendem em conjunto e constroem as bases necessárias para alcançar com êxito o conhecimento necessário do conteúdo da disciplina e sua respectiva aprovação na mesma.

Nas aulas práticas e aos encontros com os alunos foi possível perceber muitas deficiências que puderam ser contornadas por nós. A terminologia da área dos transtornos da aprendizagem e do desenvolvimento define deficiência como uma condição resultante de um impedimento, ou seja, como uma barreira em algum nível que compromete desempenhos estabelecidos (AMERICAN PSYCHIATRIC ASSOCIATION, 1995; SASSAKI, 2005).

Nos momentos em laboratório foi visível erros dos discentes ao se fazer medições dos volumes e confusão com o uso dos reagentes, devido ao nervosismo sentido na hora, e também os alunos muitas vezes não possuem o hábito de frequentar laboratório e utilizar as vidrarias, o que dificulta ainda mais. Por ocasião dos encontros os alunos trazem dúvidas que não foram tiradas em sala de aula simplesmente por omitir questionamento ao professor, muitas delas foram explicadas durante a aula, e ele não conseguiu compreender, e não se sabe ao certo os motivos de isso acontecer, mas supomos que haja duas razões, vergonha e timidez. Segundo Taglieber e Müller (2013) a timidez gera um medo de o individuo falar algo errado ou de fazer um questionamento que não tenha fundamento para outras pessoas, isto afeta uma grande parte da população tanto crianças como adultos, que se 
enxergam pressionados a mostrar suas habilidades sociais e de se relacionar com o outro.

Dentre os pontos positivos do projeto da monitoria para os alunos, podemos destacar alguns, como: maior habilidade, esclarecimento das dúvidas, interação entre monitor/aluno e professor/monitor. Não podendo esquecer que a monitoria favorece a relação entre o conhecimento e vivência da comunidade acadêmica, estimula o senso crítico, e a criatividade para com as práticas pedagógicas, trazendo também um pouco do que se passa no mercado de trabalho.

E uma parte muito importante é o elo entre orientando e orientador que se forma, para que tudo ocorra da melhor forma possível, um respeitando o espaço do outro. Tendo como objetivo final ver o desempenho do aluno na disciplina, para aumento do índice de aprovações por média e diminuição de reprovações e provas finais, além da verificação da aprendizagem e melhor aproveitamento do conhecimento da disciplina durante todo o semestre. A referida turma trabalhada teve um desempenho excelente, onde todos os educandos que permaneceram até o fim do período foram aprovados.

\section{Conclusão}

A monitoria implicou em benefícios para os alunos com relação ao processo de aprendizagem, e para as monitoras que tiveram um contato mais aproximado junto aos educandos e professora orientadora, pela contribuição no processo de ensino-aprendizagem dos educandos. Isso porque um aluno/monitor comprometido e consciente da função a ser desempenhada tende a desenvolver seu potencial docente, mostrando evolução em diversos aspectos, dentre eles o aprofundamento no conteúdo da disciplina e desenvolvimento de senso de responsabilidade.

As atividades desenvolvidas pelas monitoras além de contribuírem com o desempenho dos alunos que cursaram a disciplina durante os dois semestres, aumentaram a inserção do aluno-monitor em aspectos educacionais em uma Instituição de Ensino Superior, e fazendo com que eles adquirissem uma posição mais crítica em relação à própria formação acadêmica. 


\section{Referências}

AMERICAN PSYCHIATRIC ASSOCIATION. Manual diagnóstico e estatístico de transtornos mentais- DSM. 4 ed. Tradução Dayse Batista. Porto Alegre: Artes Médicas, 1995.

AZEVEDO, Clayte de Paula. Jovens, ensino superior e vestibular: egressos do curso técnico em química do Cefet-MT no curso de química da UFMT. Cuiabá, 2007.Dissertação (Mestrado em Educação), Programa de Pós-graduação em Educação do Instituto de Educação - UFMT.

BOAS, Benigna Maria de Freitas Villas. O projeto político-pedagógico e a avaliação. In: VEIGA, IIma Passos Alencastro; RESENDE, Lúcia Maria Gonçalves de (Org.). Escola: espaço do projeto político-pedagógico. 10. ed. Campinas, SP: Papirus, 2006. p. 179200.

BRASIL, Lei de Diretrizes e Bases da Educação Nacional - LDB. Lei № 9.364/96.

BRASIL. Lei 5.540, de 28 de novembro de 1968. Fixa normas de organização e funcionamento do ensino superior e sua articulação com a escola média, e dá outras providências. Disponível em:< http://www2.camara.leg.br/legin/fed/lei/1960-1969/lei5540-28-novembro-1968-359201-publicacaooriginal-1-pl.html> . Data de acesso: 04 de Dezembro de 2018.

DANTAS, Otilia Maria. Monitoria: Fontes de saberes à docência superior. Rev. Bras. Est. Pedagogia. [online]. Brasília. v. 95, n. 241, p. 567-589, 2014.

HABERMAS, Jürgen. Introdução: o materialismo histórico e o desenvolvimento de estruturas normativas. In: HABERMAS, Jürgen. Para a reconstrução do materialismo histórico. 2. ed. Tradução de Carlos Nelson Coutinho. São Paulo: Brasiliense, 1990. p. $12-45$.

LINS, Leandro Fragoso. et al. A Importância da Monitoria na Formação Acadêmica do Monitor. Jornada de Ensino, Pesquisa e Extensão 2009, 2009. Disponível em: < 
http://www.eventosufrpe.com.br/jepex2009/cd/resumos/r0147-1.pdf> Acesso em: 29 de agosto de 2016.

MASETTO, Marcos Tarcísio. Competência pedagógica do professor universitário. São Paulo: Summus, 2003.

MATOSO, Leonardo Magela Lopes. A importância da monitoria na formação acadêmica do monitor: um relato de experiência. Rev. Científica da escola da saúde. n. 2, Abr./Set., 2014.

NATARIO, Elisete Gomes; SANTOS, Acácia Aparecida Angeli. Programa de monitores para o ensino superior. Estudo de Psicologia, Campinas, v.27, n.3, p. 355-364, 2010.

OLIVEIRA, Lorena Alves; ROCHA, Janaina Esmeralda; PEREIRA, Vandberg Santos. Fatores que levam o aluno a engajar- se em programas de monitoria acadêmica de uma instituição de ensino superior. Revista Interfaces: Saúde, Humanas e Tecnologia, Juazeiro do Norte, v. 2, n. 4, 2014.

SASSAKI, Romeu Kazumi. Atualizações semânticas na inclusão de pessoas: deficiência mental ou intelectual? doença ou transtorno mental? Revista Nacional de Reabilitação, São Paulo, ano IX, n. 43, p. 9-10, mar./abr. 2005.

SANTOS, Valquiria Tiago.; ANACLETO, Celma. Monitorias Como Ferramenta Auxiliar para Aprendizagem da Disciplina Bioquímica: Uma Análise no UNILESTE-MG. Revista Brasileira de Ensino de Bioquímica e Biologia Molecular. ISSN: 1677-2318, 2007.

SANTOS, Thalita Lima.; NASCIMENTO, Ana Paula. A Monitoria Como Processo de Ensino-Aprendizagem: Disciplina de Agência E Transporte. 8을 ENEPE UFGD, 5은 EPEX UEMS, 2014.

SILVA, Ezequiel Theodoro (Coord.). A leitura nos oceanos da internet. São Paulo: Cortez, 2003.

TAGLIEBER, Gisele Monalisa do Carmo.; MÜLLER, José Luiz. Timidez: alunos tímidos, 2013. 